\title{
Open
}

\section{CTLA-4 promotes Foxp3 induction and regulatory $T$ cell accumulation in the intestinal lamina propria}

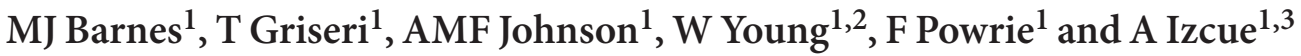

Thymic induction of $\mathrm{CD} 4^{+} \mathrm{Foxp} 3^{+}$regulatory $\mathrm{T}(\mathrm{Treg})$ cells relies on $\mathrm{CD} 28$ costimulation and high-affinity T-cell receptor (TCR) signals, whereas Foxp3 (forkhead box P3) induction on activated peripheral CD4 ${ }^{+} \mathrm{T}$ cells is inhibited by these signals. Accordingly, the inhibitory molecule CTLA-4 (cytotoxic T-lymphocyte antigen 4) promoted, but was not essential for CD4 + T-cell Foxp3 induction in vitro. We show that CTLA-4-deficient cells are equivalent to wild-type cells in the thymic induction of Foxp3 and maintenance of Foxp3 populations in the spleen and mesenteric lymph nodes, but their accumulation in the colon, where Treg cells specific for commensal bacteria accumulate, is impaired. In a T cell-transfer model of colitis, the two known CTLA-4 ligands, B7-1 and B7-2, had largely redundant roles in inducing inflammation and promoting Treg cell function. However, B7-2 proved more efficient than B7-1 in inducing Foxp3 in vitro and in vivo. Our data reveal an unappreciated role for CTLA-4 in establishing the Foxp $3^{+}$compartment in the intestine.

\section{INTRODUCTION}

$\mathrm{CD} 4^{+}$Foxp $3^{+}$regulatory $\mathrm{T}$ (Treg) cells play a key role in establishing immune homeostasis throughout life. Different mouse models and studies of patients deficient in Foxp3 (forkhead box P3) have proven that Treg cells are especially important to maintain intestinal tolerance. ${ }^{1}$ Treg cells are generated upon antigen encounter in the thymus, but they can also arise in the periphery in response to signals through the antigen receptor and soluble factors such as transforming growth factor- $\beta$ (TGF$\beta$ ) and interleukin-2 (IL-2). Peripheral induction of Foxp3 from $\mathrm{CD} 4^{+} \mathrm{Foxp}^{-} \mathrm{T}$ cells is dependent upon the strength of the signal through the T-cell receptor (TCR)-although TCR activation is needed for Foxp3 induction, strong TCR signals inhibit this induction in vitro., ${ }^{2,3}$ Similarly, costimulation through CD28 reduces the peripheral induction of Foxp3 in $\mathrm{CD}^{+}{ }^{+}$T cells. ${ }^{3,4}$ CTLA-4 (cytotoxic T-lymphocyte antigen 4 ) is a coinhibitory molecule expressed by activated $\mathrm{T}$ cells and by a large proportion of Foxp $3^{+}$Treg cells. ${ }^{5,6}$ Although the inhibitory role of CTLA-4 in T-cell activation has been known for a long time, recent studies have refined our understanding of its mode of action by showing that CTLA- 4 can inhibit
T-cell activation in a cell-extrinsic manner by endocytosis of the shared ligands of both CD28 and CTLA-4, B7-1 and B7-2. ${ }^{7,8}$ Competition with CD28 is not the only mechanism of action for CTLA-4, as it can also inhibit TCR activation in the absence of B7 molecules. ${ }^{9}$

Although the conversion of peripheral $\mathrm{CD} 4{ }^{+} \mathrm{T}$ cells into Treg cells in vitro is well documented, its relevance in vivo is less well understood. Recent data suggest that Treg cells in the colon, unlike Treg cells in other organs, are mostly generated in the periphery from $\mathrm{CD} 4^{+}$Foxp $3^{-}$precursors that express TCRs specific for microbiota-derived antigens. ${ }^{10} \mathrm{We}$ have analyzed the role of CTLA- 4 in the peripheral induction of Treg cells. Our data show that although CTLA-4 is dispensable for the induction of Treg cells in vitro, it enhances Foxp3 induction upon ligation. Accordingly, CTLA-4-deficient naive $\mathrm{CD}^{+} \mathrm{T}$ cells give rise to less Foxp $3^{+}$cells after transfer into RAG-deficient mice. Additionally, consistent with a role for peripheral Foxp3 induction in the composition of the colonic Treg cell population, CTLA- 4 enhanced the accumulation of Foxp $3^{+}$cells in the colonic lamina propria, but not the thymus, spleen, or mesenteric lymph nodes. The shared ligands

\footnotetext{
${ }^{1}$ Translational Gastroenterology Unit, Experimental Medicine Division, Nuffield Department of Clinical Medicine, University of Oxford, John Radcliffe Hospital, Oxford, UK. ${ }^{2}$ Present address: AgResearch, Food Nutrition \& Health, Food Nutrition Genomics Team, Grasslands Research Centre, Palmerston North, New Zealand. ${ }^{3}$ Present address: Max Planck Institute of Immunobiology and Epigenetics, am Stübeweg 51, Freiburg, Germany and Centre of Chronic Immunodeficiency, Universitätsklinikum Freiburg, Freiburg, Germany. Correspondence: A Izcue (izcue@ie-freiburg.mpg.de) or F Powrie (fiona.powrie@path.ox.ac.uk) 
for both CD28 and CTLA-4, B7-1 and B7-2, play redundant roles in the induction of $\mathrm{T}$ cell-transfer colitis as well as Treg cell-mediated protection from disease in this model. However, peripheral Foxp3 induction was particularly enhanced by B7-2. Overall, our data identify a differential role for CTLA- 4 and B7-2 in the induction of Foxp3 from peripheral CD4 ${ }^{+} \mathrm{T}$ cells and in the specific accumulation of Treg cells in the intestinal lamina propria.

\section{RESULTS}

\section{CTLA-4 promotes Foxp3 induction from naive T cells}

CD28 signaling has been reported to reduce Foxp3 induction when $\mathrm{T}$ cells encounter strong antigenic signals through the TCR. ${ }^{2-4}$ To assess the role of CTLA- 4 in the absence of ligand competition with CD28, we employed an antigen-presenting cell (APC)-free system using plate-bound agonistic antibodies and soluble TGF- $\beta$ and IL-2. We found that CTLA- 4 crosslinking in the presence of TCR signals enhanced the generation of Foxp $3^{+}$cells in a dose-dependent manner (Figure 1a). Moreover, CTLA-4 engagement changed the effect of CD28 crosslinking from inhibiting to promoting Foxp3 expression (Figure 1b). Enhanced induction of Foxp3 by CTLA-4 ligation did not result from reduced proliferation of Foxp $3^{-}$cells (Figure 1c). Indeed, although Foxp $3^{+}$cells had a higher division index across all concentrations of anti-CTLA- 4 tested, this was because of an increased number of nondivided cells among Foxp3- cells (Figure 1d), as Foxp3 ${ }^{-}$cells entering cell division did not show reduced proliferation compared with Foxp ${ }^{+}$cells. When cells were analyzed according to the number of times they had divided, we found that CTLA- 4 enhanced Foxp 3 expression across all generations and even in cells that did not divide (Figure 1d). Furthermore, viability of Foxp $3^{+}$cells was slightly reduced compared with Foxp $3^{-}$cells, suggesting that CTLA-4 ligation did not differentially promote the survival of Foxp $3^{+}$ cells (Figure 1e). Altogether, these observations show that CTLA-4 ligation can promote Foxp3 induction in vitro.

\section{CTLA-4 promotes Foxp ${ }^{+} \mathrm{T}$-cell generation in vivo}

Next, we assessed the ability of CTLA-4-deficient $\mathrm{CD} 4^{+} \mathrm{T}$ cells to become Foxp $3^{+} \mathrm{T}$ cells. Previous reports indicate that Foxp $3^{+}$Treg cells can still develop in the absence of CTLA4. ${ }^{11,12}$ Furthermore, Foxp $3^{+}$cells are present in an increased number in $\mathrm{Ctla-4^{-1- }}$ mice, which undergo a severe multiorgan inflammatory disease. ${ }^{9}$ In contrast to the inflamed state of Ctla-4 $4^{-/-}$mice or irradiated mice reconstituted with $\mathrm{Ctla-} 4^{-/-}$ bone marrow, irradiated mice reconstituted with mixed wildtype and $\mathrm{Ctla}-4^{-/-}$bone marrow remain healthy. ${ }^{13} \mathrm{Ctla}-4^{-/-}$ and congenically marked wild-type naive $\mathrm{T}$ cells isolated from healthy bone marrow chimeras were equally efficient at inducing Foxp3 in an in vitro system devoid of CTLA-4 or CD28 ligands (Figure 2a). This contrasts with the conclusions of an earlier study that used T cells from $\mathrm{Ctla}-4^{-/-}$mice; ${ }^{14}$ the reasons for this discrepancy are unclear but could be because of the use of cells directly isolated from $\mathrm{Ctla-} 4^{-/-}$mice, in which lymphoproliferation and aberrant immune activation begins early in life. ${ }^{15}$
To verify the effect of CTLA-4 deficiency in an in vivo model of Foxp 3 induction, we transferred naive $\mathrm{CD} 4{ }^{+} \mathrm{CD} 45 \mathrm{RB} \mathrm{B}^{\mathrm{hi}}$ $\mathrm{T}$ cells, isolated from healthy mixed chimeras, into immunodeficient mice. Transfer of naive $\mathrm{CD} 4^{+} \mathrm{T}$ cells into wild-type $\mathrm{Rag}^{-/-}$recipients induces intestinal inflammation, and this is accompanied by the induction of a small population of Foxp $3^{+}$ T cells. ${ }^{16}$ This small amount of Foxp3 induction is not sufficient to prevent inflammation unless Foxp $3^{+}$numbers are boosted, which for example occurs when Stat3-signaling cytokines such as IL-23 or IL-6 are absent. ${ }^{16}$ In this system, we could observe a markedly reduced population of Foxp $3^{+} \mathrm{T}$ cells in mice that received $\mathrm{Ctla}-4^{-/-}$T cells (Figure 2b). Following the cotransfer of $\mathrm{Ctla-} 4^{-/-}$and wild-type naive $\mathrm{CD} 4^{+} \mathrm{T}$ cells at 1:1 ratio into Rag2 $2^{-/-}$mice, wild-type Foxp $3^{+} \mathrm{T}$ cells accumulated more than Ctla- $4^{-/-}$Foxp $3^{+}$cells and Ctla-4-1- Foxp3 ${ }^{-}$T cells accumulated more than wild-type Foxp3- cells, demonstrating that the reduction in the percentage of Foxp $3^{+}$cells among Ctla- $4^{-/-}$ $\mathrm{T}$ cells was cell-intrinsic (Figure $2 \mathrm{c}$ ).

\section{Foxp3 ${ }^{+} \mathrm{T}$-cell accumulation in the intestinal lamina propria is dependent upon CTLA-4}

We decided to assess the effect of CTLA- 4 on the Foxp $3^{+}$populations in the gut under steady-state conditions by analyzing the composition of the CD4 ${ }^{+}$Foxp3 ${ }^{-}$and Foxp3 ${ }^{+}$T-cell compartments in irradiated $\mathrm{Rag}^{-/-}$mice reconstituted with congenically distinct $\mathrm{Ctla}-4^{-/-}$and wild-type bone marrow cells. In the thymus, spleen, and mesenteric lymph nodes, CTLA4-deficient and -sufficient $T$ cells contributed equally to the Foxp $3^{+}$and Foxp $3^{-}$compartments. In contrast, the contribution of CTLA-4-deficient cells to the Foxp3 ${ }^{+}$T-cell pool in the colon lamina propria was markedly impaired (Figure 3a). This was not because of a general inability of $\mathrm{Ctla}-4^{-/-}$cells to contribute to the intestinal lymphocyte pool, as $\mathrm{Ctla-4^{-/- }}$ cells contributed to the colonic Foxp3- $3^{-} D 4^{+}$T-cell population in a similar percentage as in other organs (Figure 3a). Interestingly, despite the strong reduction in CTLA-4-deficient Treg cells in the intestine, the percentage of total Foxp $3^{+}$cells was similar between mixed $\mathrm{Ctla}-4^{-/-}$and wild-type chimeras and control chimeras reconstituted with wild-type bone marrow (Figure 3b). This was achieved through a greater contribution of CTLA-4-sufficient cells to the overall colonic Foxp $3^{+}$ T-cell pool in the $\mathrm{Ctla4}^{-/-}$, but not in the control chimeras (Figure 3b). We did not find differences in the expression of the marker of cell proliferation Ki67 or gut-homing-associated molecules CD103 or $\alpha_{4} \beta_{7}$ between wild-type and Ctla-4-/Foxp $^{+}$T cells in mixed chimeras (Figure 3c). Hence, CTLA-4 determines the individual cell fate by enhancing Foxp3 induction in a cell-intrinsic way, but the total size of the colonic Foxp $3^{+} \mathrm{T}$-cell pool is regulated by cell-extrinsic factors. Our data are consistent with a specific role for CTLA- 4 in the induction of intestinal Treg cells.

\section{Redundant roles of B7-1 and B7-2 in T cell-mediated colitis}

We next sought to assess the contribution of the two known CTLA-4 ligands, B7-1 and B7-2, to the balance of pro- and antiinflammatory $\mathrm{CD}^{+}{ }^{+} \mathrm{T}$-cell responses in the gut. To this aim, 

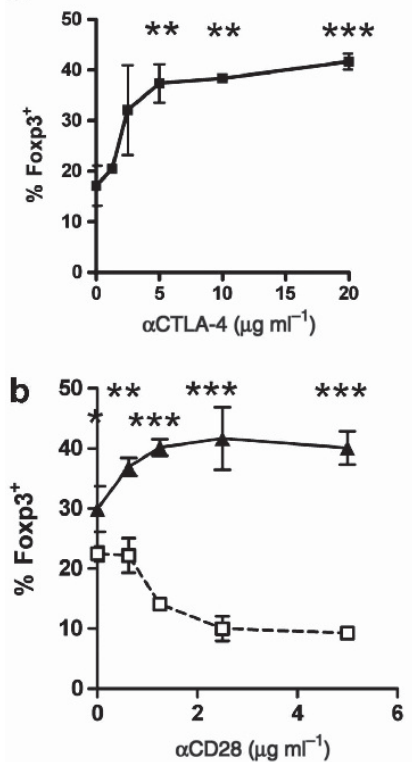

C

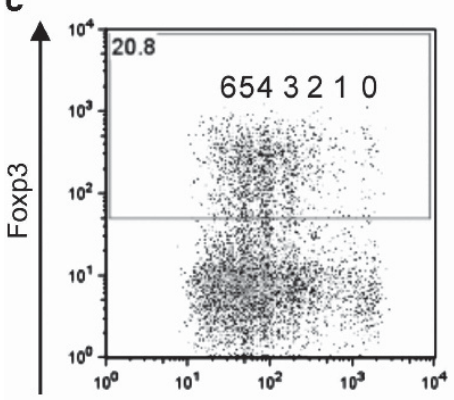

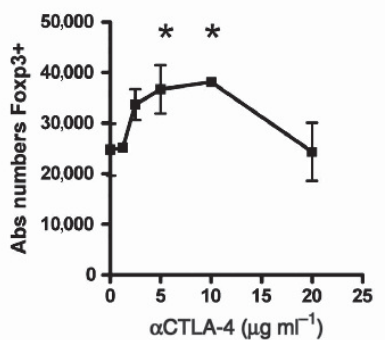
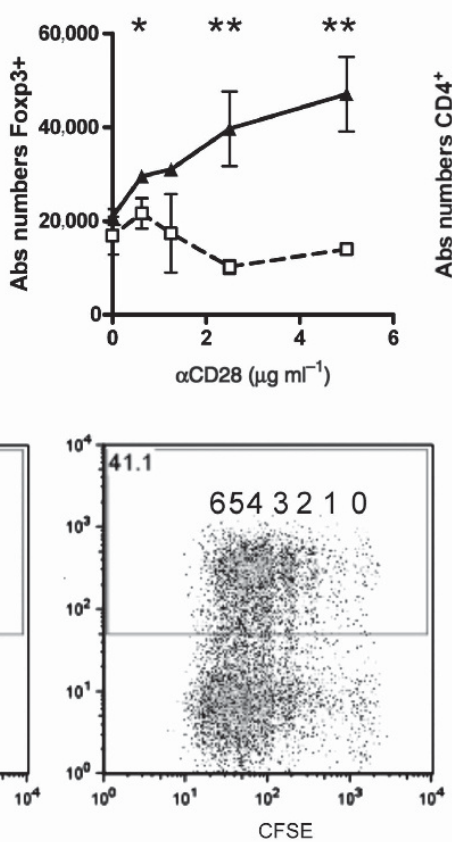
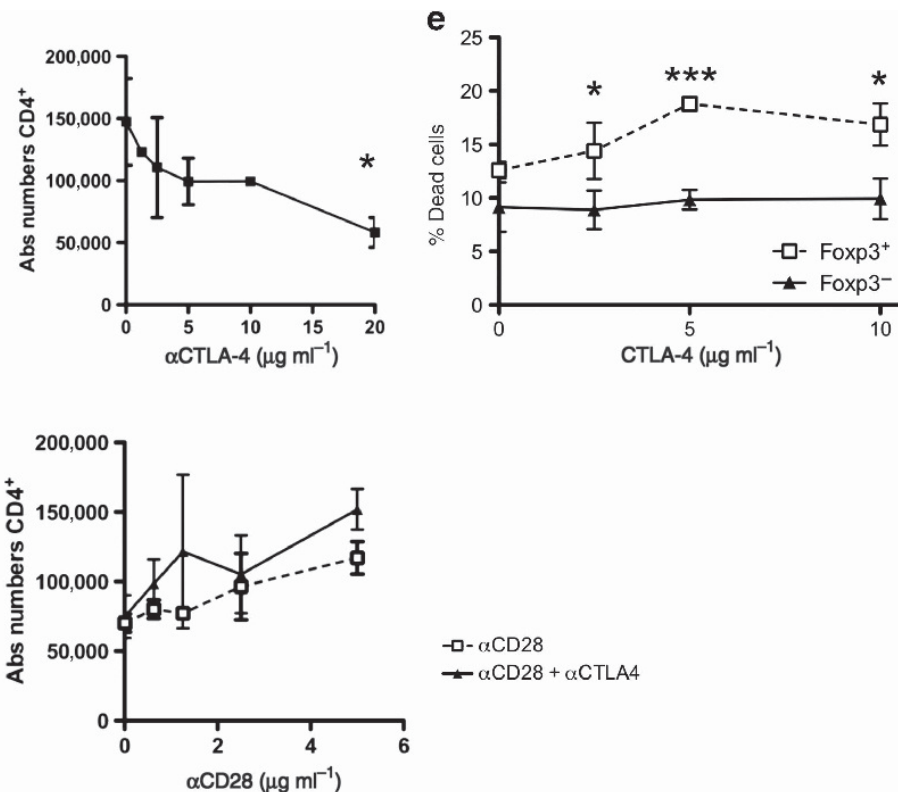

$\alpha$ CTLA-4 ( $\mu \mathrm{g} \mathrm{ml^{-1 } )}$

d

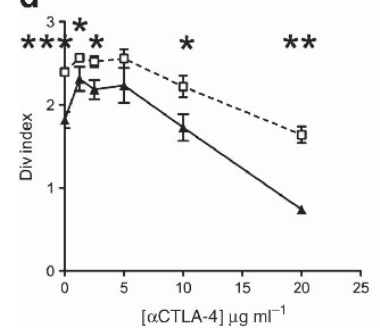

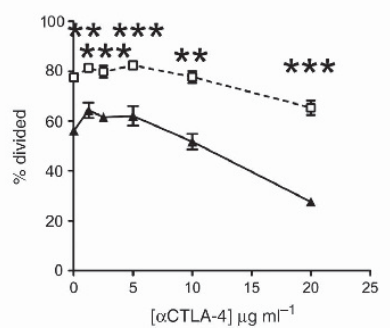
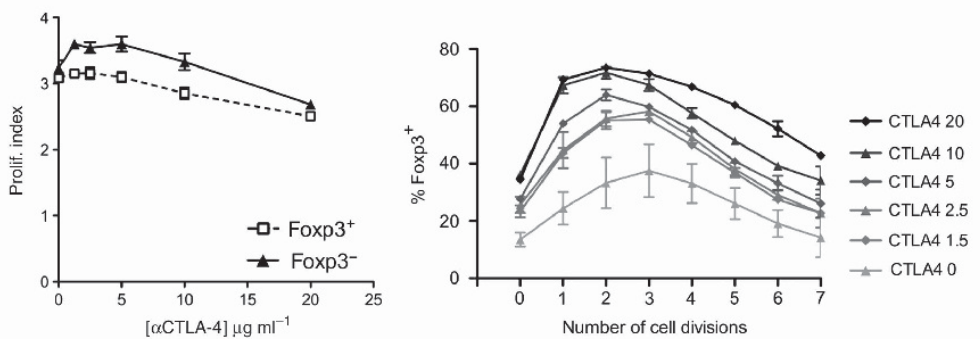

Figure 1 CTLA-4 engagement directly enhances Foxp3 induction in CD4 ${ }^{+}$T cells. (a) CTLA-4 engagement promotes the accumulation of Foxp3 ${ }^{+} \mathrm{T}$ cells in a concentration-dependent manner. The graphs show percentage and absolute (Abs) numbers (mean \pm s.d. of triplicate wells) of Foxp $3^{+}$regulatory $\mathrm{T}$ (Treg) cells after culture of naive CD4 ${ }^{+}$T cells with transforming growth factor- $\beta$ (TGF- $\beta$ ), interleukin- 2 (IL-2), plate-bound anti-CD3 $\varepsilon\left(1 \mu \mathrm{g} \mathrm{ml}^{-1}\right)$, plate-bound anti-CD28 $\left(1 \mu \mathrm{g} \mathrm{ml}^{-1}\right)$, and different concentrations of agonistic plate-bound anti-CTLA-4 in an antigen-presenting cell (APC)-free system. Asterisks indicate statistically significant differences between a given time point and time point $=0$. Absence of asterisks means "not significant". Data are representative of three independent experiments. (b) CTLA-4 engagement promotes the accumulation of Foxp3 ${ }^{+}$ T cells and synergizes with CD28 signals across a range of concentrations. Cells were cultured as for a, with $5 \mu \mathrm{g} \mathrm{ml}^{-1}$ plate-bound anti-CTLA-4 and different concentrations of agonistic anti-CD28. Asterisks indicate statistically significant differences between the presence or absence of anti-CTLA-4 at a given anti-CD28 concentration. (c) CTLA-4 favors Foxp3 induction without blocking the proliferation of Foxp3 ${ }^{+}$T cells. CFSE plots of the cultures in the same conditions as $\mathbf{b}$ (plate-bound anti-CD3 $\varepsilon$ and anti-CD28, both at $1 \mu \mathrm{g} \mathrm{ml}^{-1}$, and different concentrations of plate-bound anti-CTLA-4) are shown to assess cell proliferation. Numbers on the top left corner of the plot indicate the percentage of Foxp3 ${ }^{+}$cells; numbers $0-6$ indicate the number of divisions according to CFSE dilution. Data are representative of two independent experiments. (d) Accumulation of Foxp3 ${ }^{+}$ cells does not depend on cell proliferation. The average divisions (division index), percentage of cells that had entered division (\% divided), and the average number of divisions undergone by the cells that entered division (proliferation index) are shown. The graph on the right shows the percentage of Foxp $3^{+}$cells in each generation for different anti-CTLA-4 concentrations. Asterisks indicate statistically significant differences between Foxp3 ${ }^{+}$and Foxp3 ${ }^{-}$cells. (e) Measurement of cell death in anti-CTLA-4-induced Foxp3 ${ }^{+}$cell in vitro cultures. CD4 ${ }^{+}$T cells were cultured as in $\mathbf{b}$ and $\mathbf{c}$ and stained for Foxp3 and the Fixable Viability Dye eFlour 780. Dead cells stained positive for the viability dye and the frequency of dead cells in the Foxp3 ${ }^{+}$and Foxp3- populations is shown. Statistically significant differences between groups are indicated $\left({ }^{\star} P<0.05 ;{ }^{* *} P<0.01 ;{ }^{* * \star} P<0.001\right)$. 

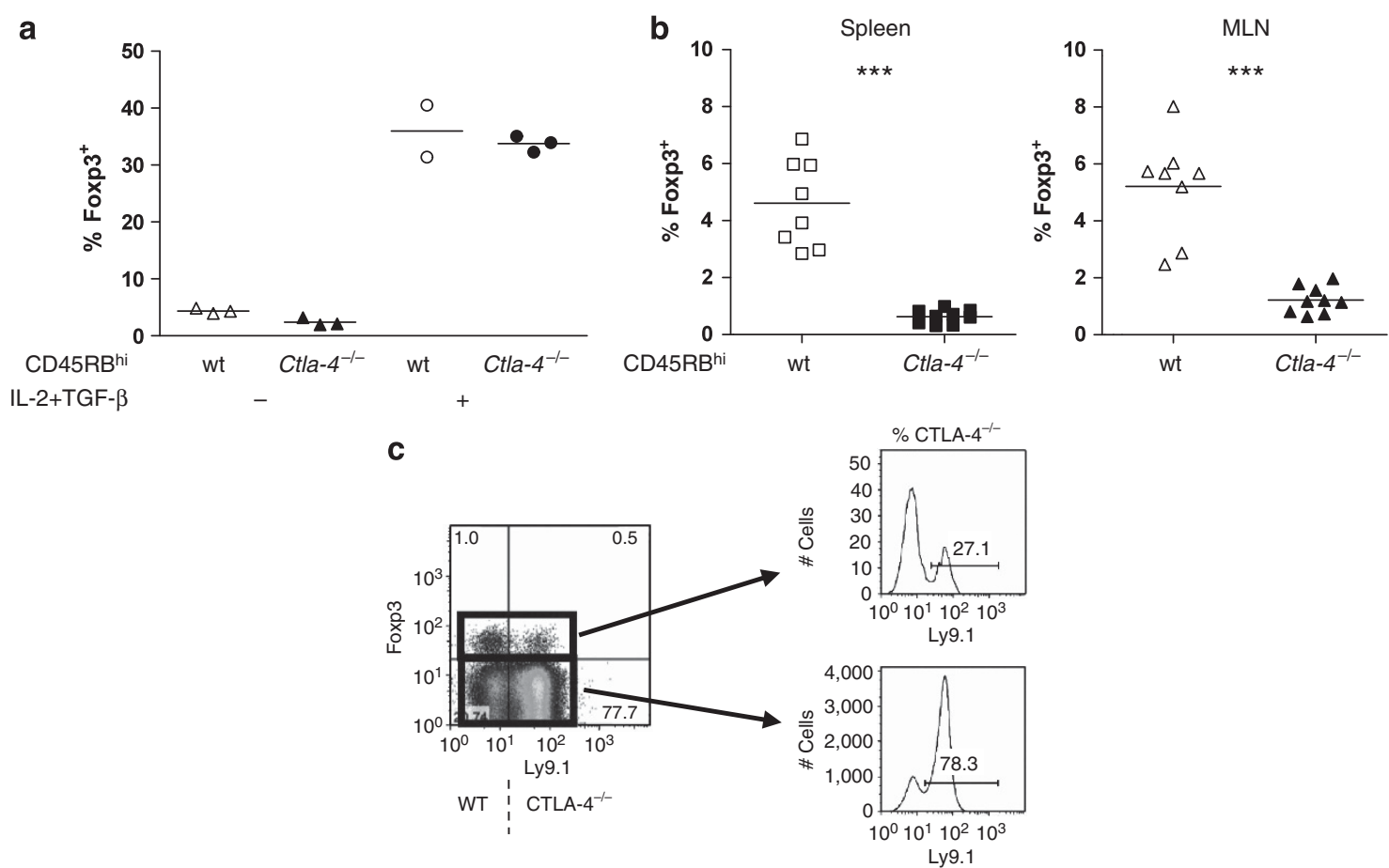

Figure 2 Induction of Foxp3 on CTLA-4-deficient T cells. (a) CTLA-4 is not required for the induction of Foxp3 ${ }^{+} \mathrm{T}_{\text {cells. Sorted wild-type (wt) }}$ or CTLA-4-deficient $C D 4{ }^{+} \mathrm{CD} 45 \mathrm{RB}^{\text {hi }} \mathrm{CD} 25^{-}$naive T cells were cultured for 3 days in an antigen-presenting cell (APC)-free system in the presence of anti-CD3 $\varepsilon$ and anti-CD28 beads, interleukin-2 (IL-2), and transforming growth factor- $\beta$ (TGF- $\beta$ ). The percentages of CD4 ${ }^{+}$T cells expressing Foxp3 are shown. Data are representative of two independent experiments. (b) CTLA-4 promotes Foxp3 ${ }^{+}$T-cell accumulation during colitis in vivo. The diagram shows Foxp3 expression among CD4 ${ }^{+}$T cells in the spleen or mesenteric lymph nodes (MLNs) 2 months after transfer of naive wt or Ctla-4-/- T cells isolated from mixed bone marrow chimeric mice. Each point represents an individual mouse. Data are pooled from two independent experiments. (c) CTLA-4 expression in T cells promotes the accumulation of Foxp3 ${ }^{+}$cells and reduces the accumulation of Foxp3cells after naive T-cell transfer. Ctla- $4^{-/-}\left(\right.$Ly9.1 $\left.1^{+}\right)$and wild-type naive T cells $\left(\right.$Ly9.1 $\left.{ }^{-}\right)$isolated from the same bone marrow chimeric animals were cotransferred in a 1:1 ratio into RAG-deficient hosts. At 2 months after transfer, Ctla-4-/- cells were enriched in the splenic CD4 ${ }^{+}$Foxp3- T-cell population (lower quadrants) but showed reduced accumulation among splenic CD4 ${ }^{+}$Foxp3 ${ }^{+} \mathrm{T}$ cells (upper quadrants). Statistically significant differences between groups are indicated $\left({ }^{\star \star \star} P<0.001\right)$.

we again used the well-characterized model of T cell-transfer colitis. ${ }^{17} \mathrm{CD} 28$-mediated costimulation has been described to be necessary for systemic and intestinal inflammation after naive T-cell transfer, ${ }^{18}$ but there are conflicting reports on the respective roles of B7-1 and B7-2 in this model. ${ }^{18,19}$ To check whether induction of disease following naive $\mathrm{CD} 4^{+} \mathrm{T}$-cell transfer is differentially affected by the absence of B7-1 or B7-2, we transferred wild-type $\mathrm{CD} 4{ }^{+} \mathrm{CD} 45 \mathrm{RB}^{\mathrm{hi}} \mathrm{CD} 25^{-}$naive $\mathrm{T}$ cells into Rag $2^{-/-}$mice genetically deficient for either costimulatory molecule. ${ }^{20,21}$ Deficiency of B7-1 or B7-2 did not abrogate wasting disease, as assessed by decrease in body weight (Figure 4a) or the concentrations of IL-12, tumor necrosis factor- $\alpha$, or interferon- $\gamma$ in the serum (Figure $\mathbf{4 b}$ ), which are key cytokines for the development of wasting disease in this model. ${ }^{22,23}$ We could detect a minor but significant increase in serum

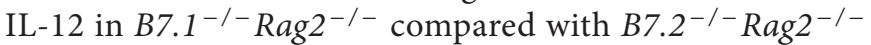
mice (Figure 4b); however, this difference was not associated with significant variations in other $\mathrm{T}$ helper type 1-produced cytokines such as interferon- $\gamma$ or tumor necrosis factor- $\alpha$.

To determine if $\mathrm{B} 7-1$ or $\mathrm{B} 7-2$ have differential roles in mucosal $\mathrm{CD} 4{ }^{+} \mathrm{T}$-cell responses, we assessed intestinal inflammation in the $\mathrm{T}$ cell-recipient $R a g 2^{-/-}$mice lacking either or both

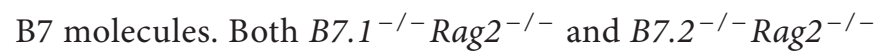
recipients developed similarly severe colitis 2 months after transfer (Figure 4c), indicating that neither molecule is essential for the induction of $\mathrm{T}$ cell-mediated intestinal inflammation. However, transfer of naive $\mathrm{CD} 4^{+} \mathrm{T}$ cells into $B 7.1^{-/-} B 7.2^{-1-}$ Rag $2^{-1-}$ mice did not induce weight loss or colitis (Figure 4a, right panel and Figure 4c, right panel), showing that either B71 or B7-2 is sufficient for the induction of pathology after T-cell transfer. Accordingly, the serum of $B 7.1^{-/-} B 7.2^{-/-}$Rag $2^{-/-}$ mice that received naive $\mathrm{T}$ cells did not show increased concentrations of interferon- $\gamma$, IL-12, or tumor necrosis factor- $\alpha$ (data not shown). In contrast to a previous study, ${ }^{24} \mathrm{~B} 7$-mediated costimulation was required for both the initial priming and perpetuation of colitogenic T-cell responses. Indeed, even the transfer of either memory/activated $\mathrm{CD} 4{ }^{+} \mathrm{CD} 45 \mathrm{RB}^{\mathrm{lo}} \mathrm{CD} 25^{-}$ $\mathrm{T}$ cells from $\mathrm{IllO}^{-/-}$mice or effector T cells isolated from colitic T cell-recipient $R a g 2^{-/-}$mice could not induce disease when transferred into $B 7.1^{-/-} B 7.2^{-/-} \mathrm{Rag}^{-/-}$recipient mice (Figure 4d and data not shown). Altogether, these results indicate that B7-1 and B7-2 play essential, overlapping roles in the induction and perpetuation of T cell-mediated colitis and wasting disease. 

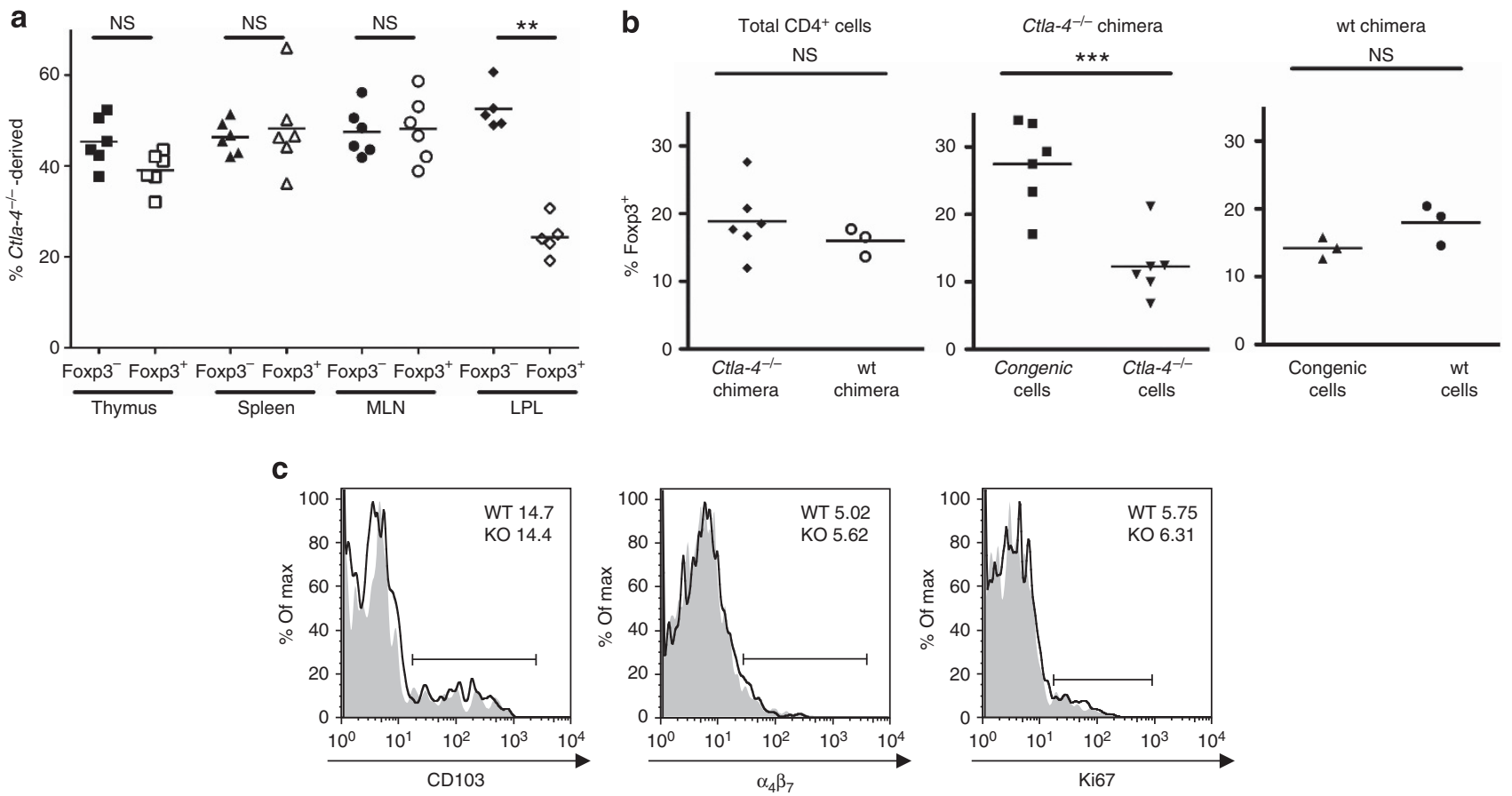

Figure 3 CTLA-4 enhances regulatory T (Treg) cell accumulation in the intestinal lamina propria. (a) Analysis of Foxp3 expression in different

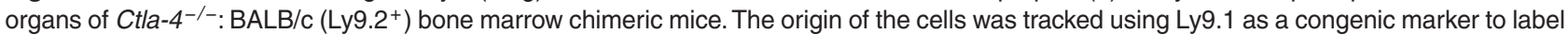
Ctla-4 $4^{-/-}$cells. The percentage of Ctla-4-/- bone marrow-derived cells among CD4 ${ }^{+}$Foxp3 ${ }^{-}$and $\mathrm{CD}^{+}{ }^{+} \mathrm{Foxp}^{+}{ }^{+} \mathrm{T}$ cells is represented in the graph showing the composition of the spleen, mesenteric lymph nodes (MLNs), and colonic lamina propria lymphocyte (LPL) T-cell populations in individual mice. The data shown are representative of three independent experiments. NS, not significant. (b) Foxp3 expression in the colonic lamina propria from Ctla-4-/-: BALB/c (Ly9.2+ $)$ and wild-type (wt): BALB/c $\left(\right.$ Ly9.2 $\left.{ }^{+}\right)$bone marrow chimeric mice. The graph shows the percentage of Foxp3 ${ }^{+}$

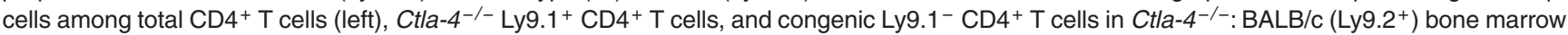
chimeric mice (middle), and wild-type Ly9.1 ${ }^{+} \mathrm{CD} 4^{+} \mathrm{T}$ cells and congenic Ly9.1- CD4+ $\mathrm{T}$ cells in wild-type: BALB/c (Ly9.2 $\left.{ }^{+}\right)$bone marrow chimeric mice. Each point represents an individual mouse. (c) Expression of CD103, $\alpha_{4} \beta_{7}$, and the proliferation marker Ki67 (intracellular) on Foxp3 ${ }^{+}$CD4 ${ }^{+}$ T cells from the MLNs of Ctla-4-/-: BALB/c $\left(\right.$ Ly9.2 $\left.{ }^{+}\right)$and wild-type: BALB/c $\left(\right.$Ly9.2 $\left.2^{+}\right)$bone marrow chimeric mice. Plots are gated on CD4+ Ly9.1+ Foxp $3^{+}$cells. Black line, Ctla- $4^{-/-}$cells; shaded gray, wild-type cells. Statistically significant differences between groups are indicated $\left({ }^{* \star} P<0.01\right.$; $\left.{ }^{* * *} P<0.001\right)$.

\section{B7-1 and B7-2 play equivalent roles in CTLA-4-mediated protection from colitis}

Cotransfer of the $\mathrm{CD} 4{ }^{+} \mathrm{CD} 45 \mathrm{RB}^{\mathrm{lo}} \mathrm{CD} 25^{+} \mathrm{T}$-cell population, which is enriched in Foxp $3^{+}$Treg cells, has been shown to prevent both the systemic and mucosal pathology induced by naive CD4 ${ }^{+}$T-cell transfer. ${ }^{6}$ Anti-CTLA- 4 antibodies or Fab fragments that block B7 binding can abrogate Treg cell-mediated regulation, indicating that protection requires engagement of the CTLA-4 extracellular domain. However, deficiency of either B7-1 or B7-2 in recipient mice did not influence the ability of Treg cells to prevent wasting disease and colitis (Figure 5a,b).

We have previously reported that protection from colitis by wild-type Treg cells is dependent on CTLA-4, but CTLA-4deficient Treg cells can develop compensatory mechanisms to mediate protection. ${ }^{12}$ To verify that protection from colitis in B7-1- and B7-2-deficient recipients still relies on CTLA-4 interactions, and as we could not induce intestinal inflammation in B7.1 ${ }^{-/-}$B7.2 $2^{-/-} \mathrm{Rag}^{-/-}$mice, we used a monoclonal antibody to block CTLA-4 function. Treatment with anti-CTLA-4 antibody abrogated Treg cell-mediated protection from colitis in wild-type, B7-1-deficient, and B7-2 deficient recipients, showing that the protection remained dependent on CTLA- 4 interactions and suggesting a redundant role for B7-1 and B7-2 in CTLA-4mediated Treg cell function (Figure 5c).

\section{B7-2 favors Foxp3 induction}

As we had identified a role for CTLA-4 in promoting peripheral Foxp3 induction, we next examined whether B7-1 and B7-2 also contributed in a similar manner to it. We again used the $\mathrm{T}$ cell-transfer model, which allowed all APCs to be wild type, B71 deficient, or B7-2 deficient. A small Foxp $3^{+}$T-cell population was again clearly detectable in B7-sufficient wild-type and B7-1deficient recipient mice (Figure 6a). In contrast, B7-2-deficient recipient mice showed a significant reduction in the frequency of Foxp $3^{+} \mathrm{T}$ cells, indicating that B7-2 may promote Foxp3 induction from peripheral $\mathrm{CD}^{+}{ }^{+} \mathrm{T}$ cells. To test this possibility using an in vitro model, we incubated naive T cells with low concentrations of anti-CD3 antibody in the presence of wild-type or B7-2-deficient dendritic cells (DCs) and the cytokines TGF- $\beta$ and IL-2 (Figure 6b). B7-2-deficient DCs were less efficient than wild-type DCs in inducing Foxp3 across a range of anti-CD3 concentrations, suggesting that B7-2 may have a specific role in the induction of Foxp3 from peripheral CD $4^{+} \mathrm{T}$ cells. Similar to the in vivo result, B7-1-deficient and wild-type DCs induced comparable percentages of Foxp $3^{+} \mathrm{T}$ cells (Figure 6b). 

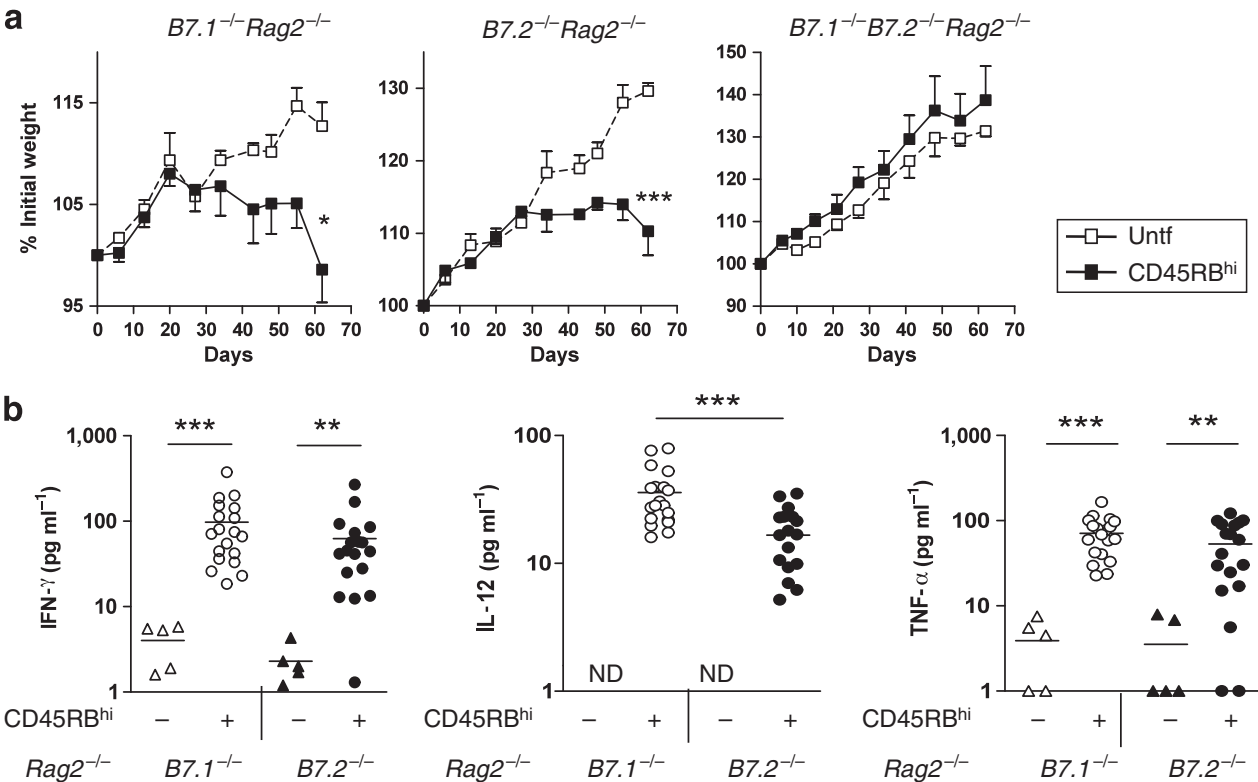

Rag2 $^{-/}$

$B 7.1^{-/-}$

B7. $2^{-/-}$
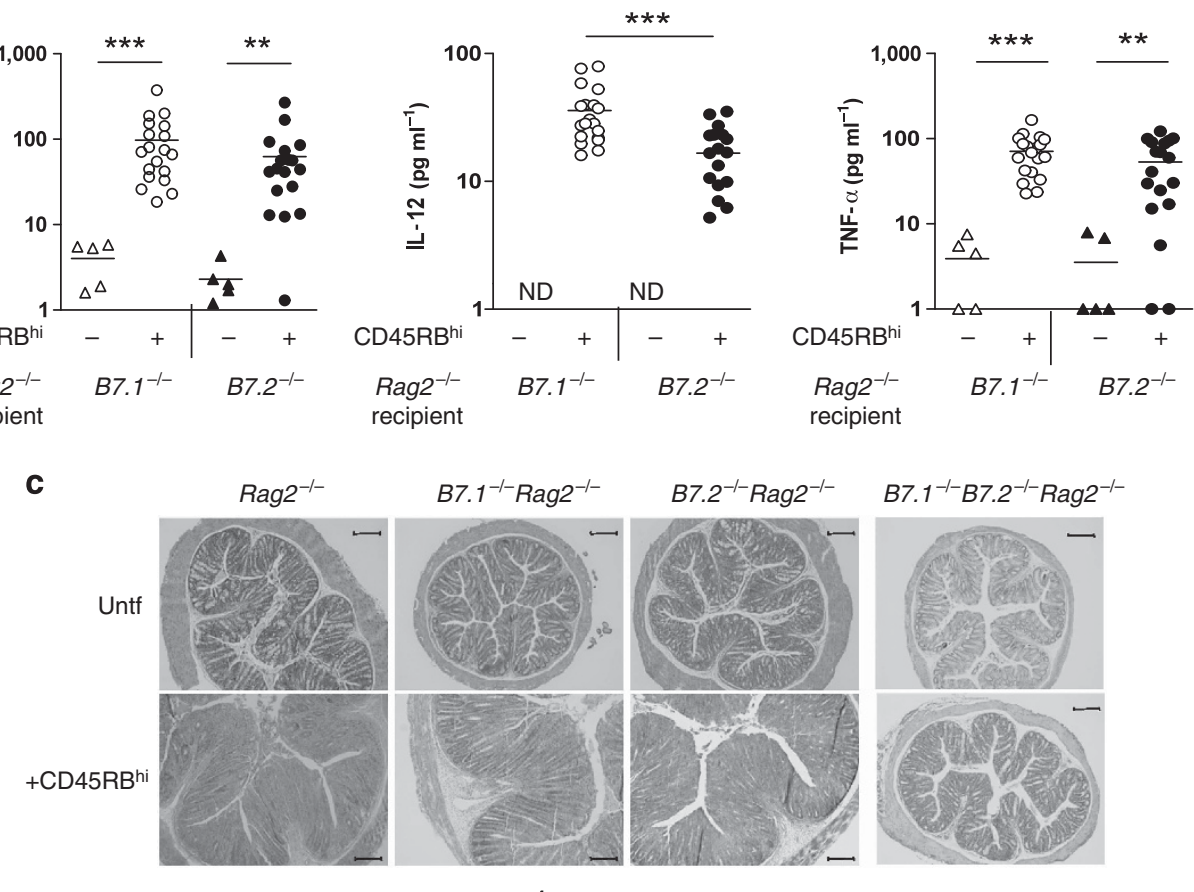

recipient

recipient
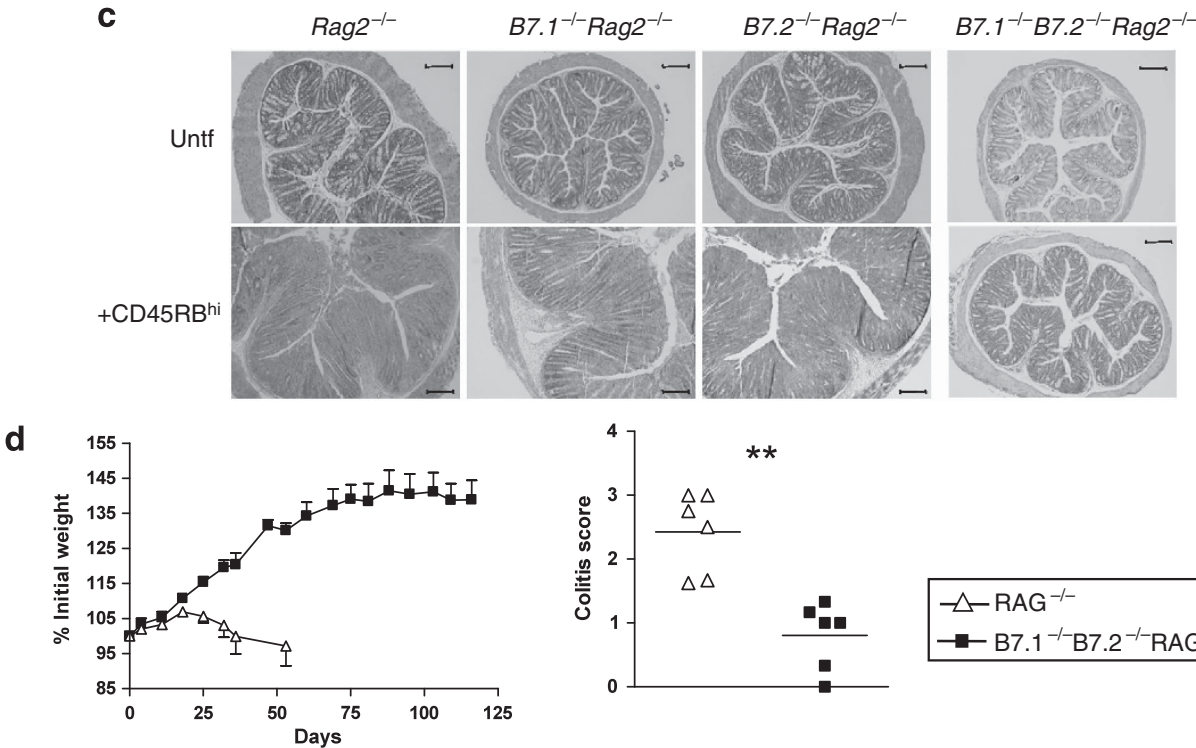

Figure 4 Expression of at least one B7 molecule on host cells is required to induce wasting disease and colitis after T-cell transfer. (a) Wasting disease can be induced by either B7-1 or B7-2. Naive CD4 ${ }^{+} \mathrm{CD} 45 \mathrm{RB}{ }^{\text {hi }} \mathrm{CD} 25^{-}$T cells were transferred into cohorts of $B 7.1^{-/-}$Rag2 $2^{-/-}, B 7.2^{-/-}$ Rag2 $2^{-/}$,- and $B 7.1^{-/-} B 7.2^{-/-}$Rag2 $2^{-/-}$mice that were subsequently weighed weekly. Data are expressed as mean \pm s.e.m. percentage of initial weight. Representative data from five independent experiments are shown ( $n=4-5$ per group). Statistics are shown for the last time point. (b) Increase of inflammatory cytokines in the serum of $B 7.1^{-/-}$Rag $2^{-/-}$, or $B 7.2^{-/-}$Rag $2^{-/-}$mice after naive T-cell transfer. Mice were killed 8-12 weeks after transfer and blood was collected by cardiac puncture. Serum cytokines were measured using a bead array system. Each point corresponds to an individual mouse; data are pooled from four independent experiments. IFN- $\gamma$; interferon- $\gamma$; ND, not detected. For interleukin-12 (IL-12) and tumor necrosis factor- $\alpha$ (TNF- $\alpha$ ) measurements, several data points were at or below the limit of detection for mice that did not receive naive T cells. (c) Colitis induction in T-cell recipients lacking B7-1 or B7-2 molecules. Representative microphotographs of

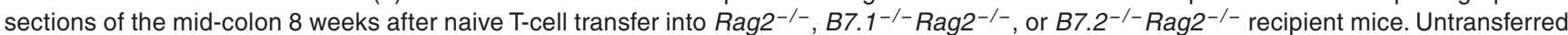
controls (Untf) and B7.1 $1^{-/} B 7.2^{-/-}$Rag $2^{-/-}$recipients 16 weeks after naive T-cell transfer are shown for comparison. Scale bars $=200 \mu \mathrm{m}$.

(d) Antigen-experienced T cells require B7 costimulation to induce disease. Weight curve (left) and colitis scores (right) from $B 7.1^{-/-B 7.2^{-/-}}$ Rag2 $^{-/-}$or costimulatory molecule-sufficient Rag2 ${ }^{-/-}$mice that received CD4 ${ }^{+}$CD25- CD45RB ${ }^{10} T$ cells from IL-10-deficient mice.

B7-sufficient $R a g 2^{-/-}$recipients were killed at week 8 because of ethical reasons, whereas $B 7.1^{-/-} B 7.2^{-/-}$Rag $2^{-/-}$recipients did not show clinical signs of disease and were left until week 17 to check for a possible delay in the onset of disease. Data on the left plot show mean weight percentage \pm s.e.m. Data on the right plot indicate the histological score of the samples taken at the time of killing the mice; each point represents an individual mouse. Statistically significant differences between groups are indicated $\left({ }^{\star} P<0.05 ;{ }^{\star \star} P<0.01 ;{ }^{\star \star \star} P<0.001\right)$. 


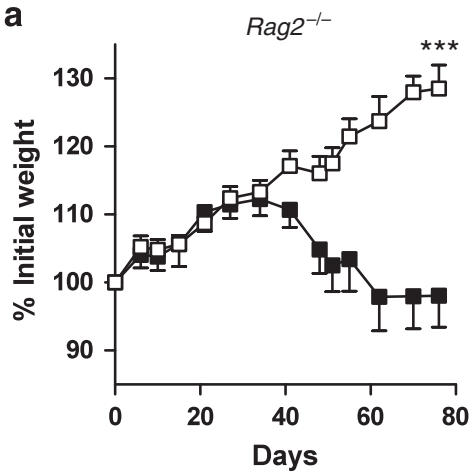

b

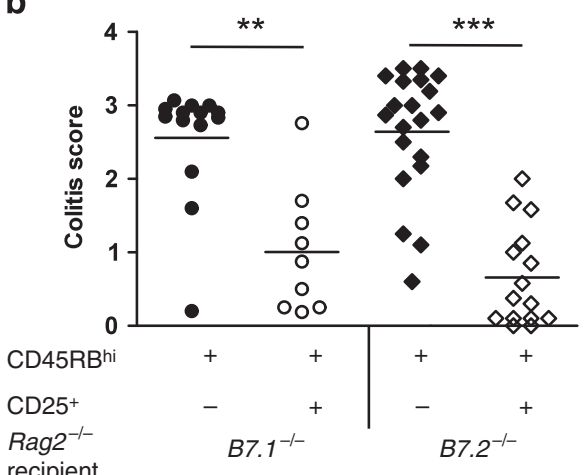

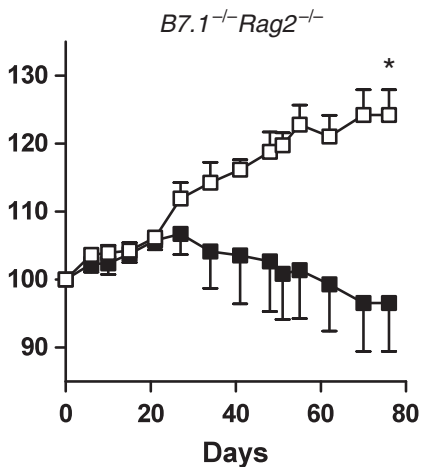

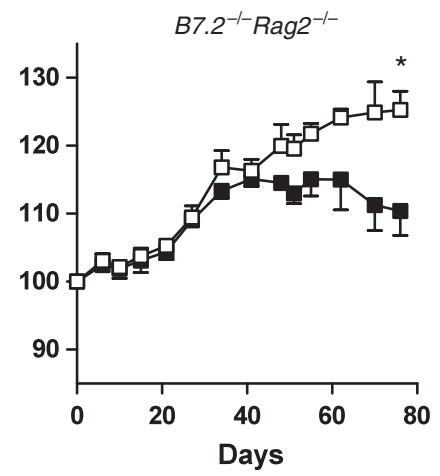

C
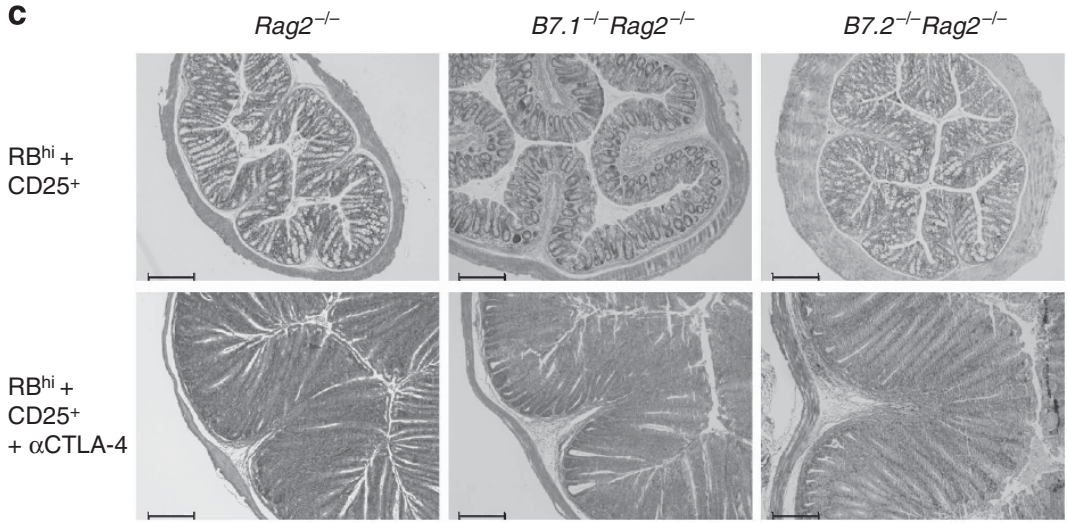

Figure $5 \mathrm{CD} 4^{+} \mathrm{CD} 25^{+}$regulatory $\mathrm{T}$ (Treg) cells can prevent $\mathrm{T}$ cell-induced wasting disease and colitis in the absence of B7-1 or B7-2. (a) Treg

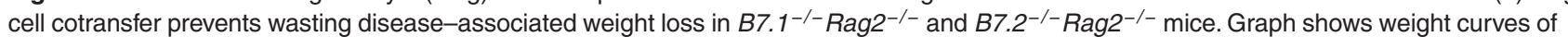

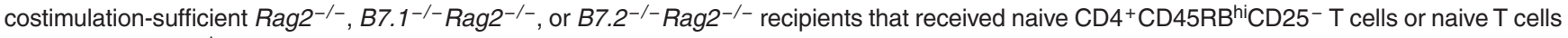
and $\mathrm{CD} 4{ }^{+} \mathrm{CD} 45 \mathrm{RB}^{\mathrm{lo}} \mathrm{CD} 25^{+}$Treg cells. Each curve represents the average weight of five mice \pm s.e.m. and is representative of four independent experiments. (b) Treg cells prevent intestinal inflammation in the absence of B7-1 or B7-2 in the recipient mice. Colitis scores of $B 7.1^{-/-}$Rag2 ${ }^{-/-}$ or $B 7.2^{-/-}$Rag $^{-/-}$recipient mice that received naive $T$ cells or naive T cells and Treg cells. Each point represents an individual mouse. Data are

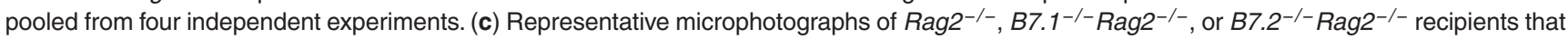
received naive $T$ cells and Treg cells, along with treatment with or without a blocking anti-CTLA-4 antibody. Data are representative of two independent experiments. Scale bars $=200 \mu \mathrm{m}$. Statistically significant differences between groups are indicated $\left({ }^{\star} P<0.05 ;{ }^{* \star} P<0.01 ;{ }^{* \star \star} P<0.001\right)$.

Finally, we decided to check the expression of B7-1 and B7-2 on different subsets of DCs in mucosal tissues. CD103 ${ }^{+}$DCs isolated from mesenteric lymph nodes have been described to preferentially induce Treg cells compared with their CD103counterparts. ${ }^{25}$ In agreement with published data, ${ }^{26}$ we found that both DC subsets express low amounts of B7-1. However, $\mathrm{CD}_{103}{ }^{+} \mathrm{DCs}$ from mesenteric lymph nodes expressed more B7-2 than CD103- DCs, which correlates with the enhanced ability of $\mathrm{CD} 103^{+}$DCs to promote Foxp3 induction in naive $\mathrm{T}$ cells (Figure 6c). Additionally, both $\mathrm{CD}_{103^{+}}$and $\mathrm{CD} 103^{-} \mathrm{DC}$ subsets showed significant B7-2 expression in the colon lamina propria (Figure 6c).

\section{DISCUSSION}

In this work we assessed how the inhibitory receptor CTLA-4 affects the peripheral induction of Foxp $3^{+} \mathrm{T}$ cells and the composition of the intestinal Treg cell pool. We found that CTLA4 acts in a cell-autonomous way to enhance Foxp3 induction following activation of naive $\mathrm{CD} 4^{+} \mathrm{T}$ cells. We also found a significant role for CTLA-4 in regulating the makeup of the colonic Treg cell pool in the steady state, suggesting that the intestinal Treg cell compartment relies more on peripheral Foxp3 induction than do Treg cell populations in secondary lymphoid organs. Our data further show that the CTLA-4 ligands B7-1 and B7-2 have overlapping functions in intestinal and systemic inflammation, and either of them can support CTLA-4-dependent Treg cell function. In addition, B7-2 specifically favors peripheral Foxp3 induction in vivo and in vitro. Our data confirm that the costimulatory requirements for the Treg cell pool in the intestine are different to the ones in the spleen and lymph nodes.

Foxp 3 is induced in the thymus and in the periphery, especially at mucosal sites, after TCR-mediated activation. ${ }^{27,28}$ Costimulation seems to play different roles in thymic vs. peripheral induction of Treg cells. In the thymus, cell-intrinsic signals through CD28 are crucial for Foxp3 expression. ${ }^{29,30}$ In contrast, CTLA- 4 does not affect Foxp $3^{+}$frequencies in thymocytes from mice with a normal TCR repertoire. CTLA-4 could still have an effect on the repertoire of Foxp $3^{+}$Treg cells, as CTLA-4 deficiency has been reported to reduce Foxp3 induction in the thymus of one TCR transgenic mouse line, but not all TCR transgenic mouse lines are affected by the lack of CTLA- $4 .{ }^{31,32}$ 

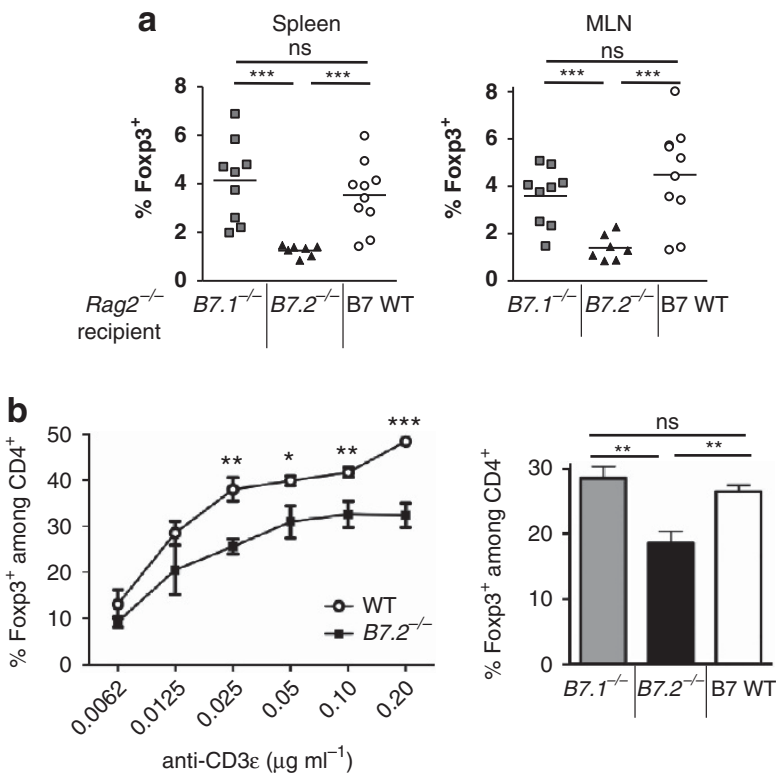

C
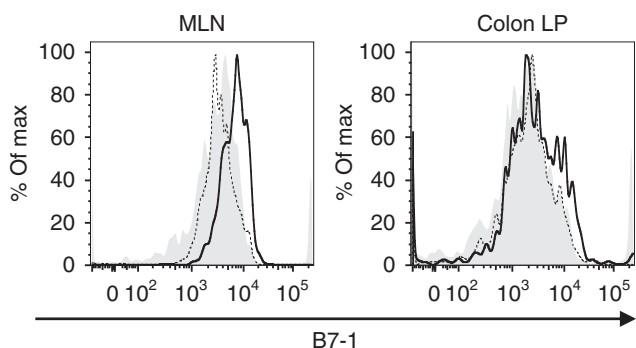

Dashed : CD103-DC Bold: $\mathrm{CD}_{103^{+} \mathrm{DC}}$ Gray: isotype

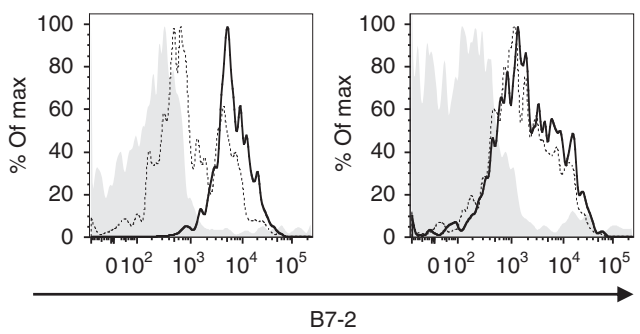

Figure 6 B7-2 rather than B7-1 promotes Foxp3 ${ }^{+}$T-cell accumulation from naive $T$ cells in vivo and in vitro. (a) Percentage of Foxp3 ${ }^{+} \mathrm{T}$ cells after naive $\mathrm{CD}^{+}{ }^{+} \mathrm{CD} 45 \mathrm{RB}^{\text {hi }} \mathrm{CD} 25^{-}$T-cell transfer into Rag2-/- recipient mice lacking B7-1 or B7-2. The diagram shows Foxp3 expression among $\mathrm{CD}^{+} \mathrm{T}$ cells in the spleen or mesenteric lymph nodes (MLNs) 2 months after transfer. Each point represents an individual mouse. Data are pooled from two independent experiments. NS, not significant. (b) A role for B7-2 expression in dendritic cell (DC)-mediated Foxp3 induction in vitro. Naive T cells and wild-type (WT) or B7.2 ${ }^{-/-}$splenic DCs were co-cultured with transforming growth factor- $\beta$ (TGF- $\beta$ ), interleukin-2 (IL-2), and indicated concentrations of agonistic anti-CD3 $\varepsilon$ antibody for 3 days (left). The mean \pm s.d. of the percentage of CD4 ${ }^{+} \mathrm{T}$ cells expressing Foxp3 is shown. Data are representative of three independent experiments. Asterisks indicate significant differences in the frequency of Foxp3 ${ }^{+} \mathrm{T}$ cells induced by wild-type or $B 7.2^{-/-}$DCs at a given anti-CD3 concentration. On the right, the percentage of Foxp3 induction when wild-type, B7-1-deficient, or B7-2-deficient DCs were cultured as before with a concentration of $0.025 \mu \mathrm{g} \mathrm{ml}^{-1}$ anti-CD3 $\varepsilon$ antibody is shown. (c) B7-1 and B7-2 expression by CD103- and CD103 ${ }^{+}$

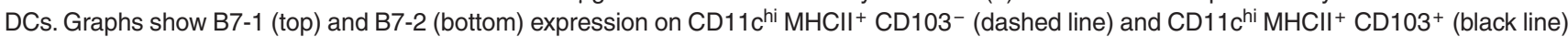
DCs isolated from mesenteric lymph nodes (left) or colonic lamina propria (right). Gray histograms show isotype control labeling for total CD11 $c^{\text {hi }}$ $\mathrm{MHCII}^{\text {hi }}$ cells. Statistically significant differences between groups are indicated $\left({ }^{\star} P<0.05 ;{ }^{\star \star} P<0.01 ;{ }^{\star \star \star} P<0.001\right)$.

In the periphery, costimulation has a different outcome as CD28 has been reported to inhibit and CTLA-4 to be essential for peripheral Foxp3 induction. ${ }^{2-4,14,33}$ Notably, CTLA-4 has been reported to be essential for TGF- $\beta$-mediated Foxp3 induction. ${ }^{14}$ However, the cells used for these experiments were isolated from $\mathrm{Ctla}-4^{-/-}$mice, which exhibit an early-onset lymphoproliferative phenotype. To circumvent this problem, we used naive $\mathrm{CD} 4^{+} \mathrm{T}$ cells isolated from healthy mixed bone marrow chimeras and found, in an APC-free system, that Foxp3 expression can be induced as efficiently in $\mathrm{Ctla}-4^{-/-}$as in wildtype $\mathrm{CD} 4^{+} \mathrm{T}$ cells. Hence, CTLA- 4 is not an essential cofactor for Foxp3 induction. However, CTLA-4 engagement still boosts peripheral Treg cell generation. We found that an agonistic antiCTLA-4 antibody directly increased the frequency and total number of Treg cells generated in vitro, suggesting that CTLA4 can enhance Foxp3 induction by modulating T cell-intrinsic signaling, and not through ligand competition with CD28 or by initiating B7-mediated signals into the APCs. Furthermore, naive $\mathrm{Ctla}^{-/-}$cells isolated from healthy bone marrow chimeras showed reduced accumulation of Foxp $3^{+}$cells after transfer into lymphopenic hosts and induction of colitis. The precise mechanisms of CTLA-4 signaling are still poorly understood and further research is needed to identify the signaling pathway that leads to Foxp 3 induction. Previous reports have suggested that strong TCR or CD28 signals reduce Foxp3 induction. ${ }^{2-4}$
CTLA-4 could have a positive effect on Foxp3 induction by dampening these signals.

To assess whether CTLA- 4 also plays a nonredundant role in peripheral Treg cell induction under nonlymphopenic steadystate conditions, we analyzed mixed bone marrow chimeric mice. In these mice, $\mathrm{Ctla}-4^{-/-}$and wild-type T cells equivalently contributed to the Treg cell and nonregulatory T-cell pools in the lymphoid organs. However, in the intestine, a widely acknowledged site of peripheral Treg cell accumulation, ${ }^{10,28}$ there was a clear deficit of $\mathrm{Ctla}-4^{-/-}$Foxp $3^{+}$cells, whereas the frequencies of $\mathrm{Ctla}-4^{-/-}$Foxp3 ${ }^{-}$cells were normal. The normal accumulation of $\mathrm{Ctla}-4^{-/-} \mathrm{CD} 4^{+} \mathrm{Foxp}^{-} \mathrm{T}$ cells in the intestine rules out general defects in the ability of CTLA-4-deficient lymphocytes to migrate to the gut. Hence, these results are fully compatible with a role for CTLA-4 in peripheral Foxp3 induction. Furthermore, they suggest that in normal mice the Foxp $3^{+}$T-cell repertoire derives mostly from thymic Treg cells in lymphoid organs, but that there is an important contribution of peripheral Foxp3 induction in other organs such as the intestine.

Comparison of $\mathrm{Ctla}-4^{-/-}$and wild-type control chimeras also shows that the size of the total intestinal Foxp $3^{+}$T-cell pool remains constant, irrespective of the contribution of each subpopulation. It has previously been shown that the size of the Treg cell population is controlled by cell-extrinsic factors. ${ }^{34}$ This raises the interesting possibility that under 
certain circumstances, lack of peripherally induced Treg cells could be numerically compensated for by a higher contribution of thymic Treg cells. Alternatively, there might be defined niches for thymic and induced Treg cells, and wild-type induced Treg cells could be populating the lamina propria at the expense of CTLA-4-deficient induced Treg cells in the mixed bone marrow chimeras. The relative contribution of different Treg cell generation pathways to immune tolerance in the gut still remains to be fully established.

The role of the shared CD28 and CTLA-4 ligands B7-1 and B7-2 in the induction of intestinal inflammation after naive Tcell transfer into RAG-deficient recipients has been controversial. Liu et al. ${ }^{18}$ reported that blocking B7-1, but not B7-2, with specific antibodies abrogated the development of colitis after naive T-cell transfer. In contrast, a subsequent report described rapid wasting disease and accelerated colitis as early as 2 weeks after T-cell transfer into Rag2 ${ }^{-/-}$recipient mice deficient for either B7-1 or B7-2, but no disease in B7-1 and B7-2 doubledeficient Rag2 ${ }^{-/-}$recipient mice. ${ }^{19}$ Our studies show that B7-1 and B7-2 expression on host cells play interchangeable roles in the induction of colitis, and that B7-1 expression is not an absolute requirement. In our hands, neither B7-1 nor B7-2-deficient hosts underwent rapid weight loss nor accelerated colitis after $\mathrm{T}$-cell transfer. The reasons for this discrepancy with the previous reports are unclear and could be related to differences in the intestinal microbiota. We note that the study reported here was carried out in a Helicobacter-free facility in which $I l 10^{-/-}$ mice do not develop spontaneous colitis by 5 months of age. All in all, our observations are consistent with an essential function for B7-mediated costimulation in the development of colitis that can be exerted either through B7-1 or B7-2 with similar consequences for systemic and mucosal inflammation.

In addition to dampening effector $\mathrm{T}$-cell responses, the $\mathrm{B} 7$ ligand CTLA-4 is important for Treg cell function and prevention of colitis. Blockade of CTLA-4 in mouse models abrogates Treg cell-mediated protection ${ }^{5,6,35}$ and, similarly, blocking CTLA-4 in cancer patients increases not only antitumor immune responses, but also the occurrence of autoimmunity and intestinal inflammation. ${ }^{36}$ CTLA-4-deficient Treg cells isolated from healthy bone marrow chimeric mice can suppress inflammation in vivo, but this protection is anti-CTLA- 4 resistant, indicating that anti-CTLA-4 antibody needs to target Treg cells to break regulation. ${ }^{12}$ Also consistent with a role for CTLA- 4 in Treg cell function, bone marrow from Ctla- $4^{-/-}$and $\mathrm{Foxp}^{-/-}$mice cannot complement each other when reconstituting lethally irradiated mice, and mice with a Foxp3-Cre-driven deletion of Ctla-4 in Treg cells develop a lethal autoimmune syndrome. ${ }^{37,38}$ The reasons why Treg cell function is dependent on CTLA- 4 are still unclear. CTLA-4 has been shown to reduce the amounts of B7 molecules on APCs through trans-endocytosis; ${ }^{8,38}$ whether this is the main function of CTLA- 4 in Treg cell-mediated protection from colitis remains to be addressed.

Despite the abundance of studies on the role of CTLA-4 in Foxp $3^{+}$Treg cell function, the question of which is the relevant ligand for Treg cells has not been answered. Here, using a CTLA4-blocking antibody instead of $\mathrm{Ctla}-4^{-/-}$Treg cells, which can use CTLA-4-independent regulatory pathways, we show that CTLA-4-mediated regulation can occur in the absence of either B7-1 or B7-2 on the host cells, suggesting that both molecules serve largely overlapping roles in tolerogenic as well as inflammatory processes. In addition to binding CD28 and CTLA-4, B7-1 is also a ligand for PD-L1, another costimulatory molecule expressed by activated T cells and Treg cells. ${ }^{39}$ This interaction does not appear to be crucial in our system, as B7-1-deficient mice did not show significantly altered immune responses.

In contrast to their overlapping roles during the induction and prevention of colitis, B7-1 and B7-2 appear to play different roles for Foxp3 induction. After transferring naive T cells into RAGdeficient mice, the frequency of Foxp $3^{+}$Treg cells induced in B7-2-deficient recipients was strongly reduced compared with B7-wild-type or B7-1-deficient recipients. The reduction in B7-2-deficient recipients was similar in magnitude to the one observed after transfer of CTLA-4-deficient T cells into RAGdeficient hosts, suggesting that B7-2 interactions with CTLA-4 might be important for Foxp3 induction. Furthermore, B7-2deficient DCs supported less Foxp3 induction over a range of anti-CD3 concentrations. This finding correlates with a report suggesting a role for B7-2 in promoting Treg cell homeostasis. ${ }^{40}$ This result was quite unexpected as most studies on B7 family member interactions suggest that B7-1 is the preferred ligand for CTLA- $4,{ }^{41,42}$ and some reports proposed a role for B7-1 in Treg cell function in vitro. ${ }^{43}$ However, our results show that B7-1 is largely dispensable for CTLA-4-dependent Foxp3 induction in vivo.

In summary, we have shown that the intestinal Treg cell compartment, unlike the one in the spleen or mesenteric lymph nodes, is dependent on CTLA-4. This is likely because of an effect on Treg cell induction, as CTLA-4 engagement favors Foxp3 induction from naive precursors and the colonic Treg cell compartment seems to be uniquely shaped by microbiotaderived antigens. ${ }^{10,28}$ In contrast to the overlapping roles of the CTLA-4 ligands B7-1 and B7-2 during intestinal inflammation and Treg cell-mediated protection from colitis, B7-2 appears to favor peripheral Foxp3 induction more than B7-1. Our results identify CTLA- 4 as a key factor that regulates the composition of the Foxp $3^{+}$T-cell population in the intestine.

\section{METHODS}

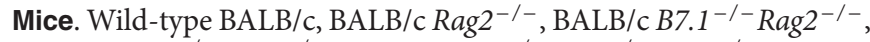

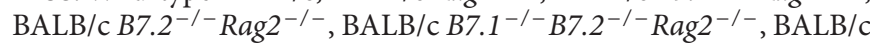
$\mathrm{Il10}^{-/-}$, and BALB/c.C57B10D2.Ly9.2 congenic and BALB/c Ctla$4^{-/-}$mice were bred and maintained under specific pathogen-free conditions in accredited animal facilities at the University of Oxford. B7-deficient mice generously donated by Arlene Sharpe (Boston, MA)

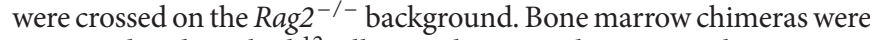
generated as described. ${ }^{12}$ All procedures involving animals were conducted according to the requirements and with the approval of the UK Home Office Animals (Scientific Procedures) Acts, 1986. Mice were negative for Helicobacter spp. and other known intestinal pathogens and were $>6$ weeks old when first used except for the bone marrow chimera donors, which were killed earlier as described.

T-cell transfer and ex vivo analysis. Different T-cell subsets were isolated from the spleens of $\mathrm{BALB} / \mathrm{c}$ or $\mathrm{BALB} / \mathrm{c} I l 10^{-/-}$mice using 
fluorescence-activated cell sorting (FACS) as previously described. ${ }^{6}$ In brief, after enriching for $\mathrm{CD} 4^{+}$lymphocytes, single-cell suspensions were stained with PerCP-conjugated anti-CD4, phycoerythrinconjugated anti-CD25, and fluorescein isothiocyanate-conjugated anti-CD45RB (all obtained from BD Biosciences, Franklin Lakes, NJ). Naive CD $4{ }^{+} \mathrm{CD} 25^{-} \mathrm{CD} 45 \mathrm{RB}^{\text {hi }} \mathrm{T}$ cells, regulatory $\mathrm{CD} 4{ }^{+} \mathrm{CD} 25^{+} \mathrm{CD} 45 \mathrm{RB}^{\text {low }} \mathrm{T}$ cells, and antigen-experienced $\mathrm{CD} 4{ }^{+}$ CD25-CD45RB ${ }^{-}$low $\mathrm{T}$ cells were purified (>99\%) with a cell sorter (MoFlo; Dako Cytomation, Glostrup, Denmark). Foxp3 expression on naive and Treg cells was routinely $1 \%$ and $95 \%$, respectively. ${ }^{16}$ Sex-matched Rag $2^{-/-}$recipient mice received $4 \times 10^{5}$ $\mathrm{CD} 4{ }^{+} \mathrm{CD} 25^{-} \mathrm{CD} 45 \mathrm{RB}^{\text {hi }}$ or $\mathrm{CD} 44^{+} \mathrm{CD} 25^{-} \mathrm{CD} 45 \mathrm{RB}^{\text {low }} \mathrm{T}$ cells by intraperitoneal injection. Additionally, some mice received $10^{5} \mathrm{CD}^{+}$ $\mathrm{CD} 25^{+} \mathrm{T}$ cells. Mouse weight was assessed weekly, and development of intestinal inflammation was monitored as described below. Mice losing in excess of $20 \%$ of initial body weight or showing signs of severe disease were humanely killed. Colons were removed from mice and fixed in buffered $10 \%$ formalin. Paraffin-embedded sections $(6 \mu \mathrm{m})$ were cut and stained with hematoxylin and eosin, and scored in a blinded fashion as described. ${ }^{12}$

Some of the recipient mice were treated intraperitoneally with $0.2 \mathrm{mg}$ of anti-mouse CTLA-4 IgG (clone UC10-4F10-11) ${ }^{44}$ three times a week for the duration of the experiment. The antibody was purified from hybridoma supernatant by affinity chromatography and shown to contain $<1.0 \mathrm{EU}$ endotoxin per mg of protein.

For analysis of congenic mice, anti-Ly9.1 was used (BD Biosciences). Lymphocytes from the colonic lamina propria were isolated as described. ${ }^{16}$

Cytokine analysis. Blood was obtained from mice by intracardiac puncture immediately after killing. Serum was separated by centrifugation using Microtainer SST tubes (BD Biosciences) following the instructions of the manufacturer and stored at $-20^{\circ} \mathrm{C}$. Cytokine concentrations were assessed using a Mouse Inflammation Cytometric Bead Array kit (BD Biosciences) following the instructions of the manufacturer and the samples were analyzed with a FACScan or FACSCalibur (BD Biosciences).

In vitro Foxp3 induction. Sorted $\mathrm{CD} 4{ }^{+} \mathrm{CD} 25^{-} \mathrm{CD} 45 \mathrm{RB}$ hi $\mathrm{T}$ cells from $\mathrm{BALB} / \mathrm{c}$ mice were resuspended in complete RPMI $5 \%$ fetal calf serum and incubated at $5 \times 10^{5}$ cells per $\mathrm{ml}$ in the presence of Dynabeads Mouse CD3/CD28 T-cell expander $\left(2 \mu \mathrm{ml}^{-1}\right.$, Invitrogen, Carlsbad, CA) or plastic-coated anti-CD3 $\left(1 \mu \mathrm{g} \mathrm{ml}^{-1}\right.$, clone 145-2C11, eBioscience, San Diego, CA) with or without anti-CD28 $\left(1 \mu \mathrm{g} \mathrm{ml}^{-1}\right.$, clone 37.51 , eBioscience) and/or anti-CTLA-4 (clone UC10-4F10-11) and in the presence of TGF- $\beta 1$ ( $1 \mathrm{ng} \mathrm{ml}^{-1}, \mathrm{R} \& \mathrm{D}$, Minneapolis, MN) and recombinant human IL-2 (100 $\mathrm{Uml}^{-1}$, Peprotech, Rocky Hill, NJ). Foxp3 (clone FJK-16s, eBioscience) expression and cell viability (Fixable Viability Dye eFlour 780, eBioscience) was assessed by flow cytometry after $72 \mathrm{~h}$. Cells were labeled with CFSE (Invitrogen) following the instructions of the manufacturer. Cell divisions were analyzed using Flow Jo software (Ver 8.8.7, Tree Star, Ashland, OR).

For the assay for DC function, CD $11 \mathrm{c}^{\text {hi }}$ cells from $B 7.2^{-/-}$ and wild-type BALB/c were sorted as described ${ }^{25}$ and plated in 96-well plates at $1 \times 10^{4}$ cells per well in RPMI $5 \%$ fetal calf serum with IL-2 $\left(100 \mathrm{U} \mathrm{ml}^{-1}\right)$ and TGF- $\beta\left(1 \mathrm{ng} \mathrm{ml}^{-1}\right)$, together with $1 \times 10^{5}$ sorted $\mathrm{CD} 4{ }^{+} \mathrm{CD} 25^{-} \mathrm{CD} 45 \mathrm{RB}^{\text {hi }} \mathrm{T}$ cells from BALB/c mice.

Statistical analysis. Weights and colitis scores were compared using the Mann-Whitney test, and cell frequencies and concentrations of proinflammatory cytokines were compared using an unpaired Student's $t$-test. Paired Student's $t$-test was used to compare Foxp $3^{+}$frequencies between Ly9.1 ${ }^{+}$and Ly9.1 ${ }^{-}$cells in mixed bone marrow chimeric mice. Differences were considered statistically significant when $P<0.05$ $\left({ }^{\star} P<0.05 ;{ }^{* \star} P<0.01 ;{ }^{* *} P<0.001\right)$. Horizontal lines in the graphs represent the mean value for each group.

\section{ACKNOWLEDGMENTS}

We are grateful to Arlene Sharpe (Harvard Medical School, Boston, MA) for the generous donation of the B7.1-, B7.2-, and CTLA-4-deficient strains. We thank Nigel Rust for assistance with cell sorting, Liz Darley and Richard Stillion for processing of histological samples, and the staff of the University of Oxford for excellent animal care. We also thank George Song-Zhao for his help with histology samples and Maria Brack for her help with dendritic cells. F.P. and her lab are supported by the Wellcome Trust. A.I. was also supported by a fellowship from the Spanish Ministerio de Educacion y Ciencia, and M.J.B. by a scholarship from the Skaggs Foundation.

\section{DISCLOSURE}

The authors declared no conflict of interest.

(C) 2013 Society for Mucosal Immunology

\section{REFERENCES}

1. Izcue, A., Coombes, J.L. \& Powrie, F. Regulatory lymphocytes and intestinal inflammation. Annu. Rev. Immunol. 27, 313-338 (2009).

2. Molinero, L.L., Miller, M.L., Evaristo, C. \& Alegre, M.L. High TCR stimuli prevent induced regulatory $T$ cell differentiation in a NF-kappaBdependent manner. J. Immunol. 186, 4609-4617 (2011).

3. Gabrysova, L. et al. Integrated T-cell receptor and costimulatory signals determine TGF-beta-dependent differentiation and maintenance of Foxp3+ regulatory T cells. Eur. J. Immunol. 41, 1242-1248 (2011).

4. Benson, M.J., Pino-Lagos, K., Rosemblatt, M. \& Noelle, R.J. All-trans retinoic acid mediates enhanced $T$ reg cell growth, differentiation, and gut homing in the face of high levels of co-stimulation. J. Exp. Med. 204, 1765-1774 (2007)

5. Takahashi, T. et al. Immunologic self-tolerance maintained by CD25(+)CD4(+) regulatory T cells constitutively expressing cytotoxic T lymphocyte-associated antigen 4. J. Exp. Med. 192, 303-310 (2000).

6. Read, S., Malmstrom, V. \& Powrie, F. Cytotoxic T lymphocyte-associated antigen 4 plays an essential role in the function of CD25(+)CD4(+) regulatory cells that control intestinal inflammation. J. Exp. Med. 192, 295-302 (2000).

7. Onishi, Y., Fehervari, Z., Yamaguchi, T. \& Sakaguchi, S. Foxp3+ natural regulatory $T$ cells preferentially form aggregates on dendritic cells in vitro and actively inhibit their maturation. Proc. Natl. Acad. Sci. USA 105, 10113-10118 (2008)

8. Qureshi, O.S. et al. Trans-endocytosis of CD80 and CD86: a molecular basis for the cell-extrinsic function of CTLA-4. Science 332, 600-603 (2011).

9. Bour-Jordan, H. \& Bluestone, J.A. Regulating the regulators: costimulatory signals control the homeostasis and function of regulatory $T$ cells. Immunol. Rev. 229, 41-66 (2009).

10. Lathrop, S.K. et al. Peripheral education of the immune system by colonic commensal microbiota. Nature 478, 250-254 (2011).

11. Tang, Q. et al. Distinct roles of CTLA-4 and TGF-beta in CD4+CD25+ regulatory T cell function. Eur. J. Immunol. 34, 2996-3005 (2004).

12. Read, S. et al. Blockade of CTLA-4 on CD4+CD25+ regulatory T cells abrogates their function in vivo. J. Immunol. 177, 4376-4383 (2006).

13. Bachmann, M.F., Kohler, G., Ecabert, B., Mak, T.W. \& Kopf, M. Cutting edge: lymphoproliferative disease in the absence of CTLA-4 is not T cell autonomous. J. Immunol. 163, 1128-1131 (1999).

14. Zheng, S.G. et al. TGF-beta requires CTLA-4 early after T cell activation to induce FoxP3 and generate adaptive CD4+CD25+ regulatory cells. J. Immunol. 176, 3321-3329 (2006).

15. Chambers, C.A., Cado, D., Truong, T. \& Allison, J.P. Thymocyte development is normal in CTLA-4-deficient mice. Proc. Natl. Acad. Sci. USA 94, 9296-9301 (1997).

16. Izcue, A. et al. Interleukin-23 restrains regulatory $T$ cell activity to drive T cell-dependent colitis. Immunity 28, 559-570 (2008).

17. Powrie, F., Leach, M.W., Mauze, S., Caddle, L.B. \& Coffman, R.L. Phenotypically distinct subsets of CD4+ T cells induce or protect from chronic intestinal inflammation in C. B-17 scid mice. Int. Immunol. 5, 1461-1471 (1993).

18. Liu, Z. et al. B7 interactions with CD28 and CTLA-4 control tolerance or induction of mucosal inflammation in chronic experimental colitis. J. Immunol. 167, 1830-1838 (2001). 
19. Kim, G., Levin, M., Schoenberger, S.P., Sharpe, A. \& Kronenberg, M. Paradoxical effect of reduced costimulation in T cell-mediated colitis. J. Immunol. 178, 5563-5570 (2007).

20. Borriello, F. et al. B7-1 and B7-2 have overlapping, critical roles in immunoglobulin class switching and germinal center formation. Immunity 6, 303-313 (1997)

21. Freeman, G.J. et al. Uncovering of functional alternative CTLA-4 counterreceptor in B7-deficient mice. Science 262, 907-909 (1993).

22. Hue, S. et al. Interleukin-23 drives innate and T cell-mediated intestinal inflammation. J. Exp. Med. 203, 2473-2483 (2006).

23. Powrie, F. et al. Inhibition of Th1 responses prevents inflammatory bowel disease in scid mice reconstituted with CD45RBhi CD4+ T cells. Immunity 1, 553-562 (1994).

24. Lohr, J., Knoechel, B., Jiang, S., Sharpe, A.H. \& Abbas, A.K. The inhibitory function of $\mathrm{B} 7$ costimulators in $\mathrm{T}$ cell responses to foreign and self-antigens. Nat. Immunol. 4, 664-669 (2003).

25. Coombes, J.L. et al. A functionally specialized population of mucosal CD103+ DCs induces Foxp3+ regulatory T cells via a TGF-beta and retinoic acid-dependent mechanism. J. Exp. Med. 204, 1757-1764 (2007).

26. Johansson-Lindbom, B. et al. Functional specialization of gut CD103+ dendritic cells in the regulation of tissue-selective T cell homing. J. Exp. Med. 202, 1063-1073 (2005).

27. Curotto de Lafaille, M.A. \& Lafaille, J.J. Natural and adaptive foxp3+ regulatory T cells: more of the same or a division of labor? Immunity 30 , 626-635 (2009).

28. Hadis, U. et al. Intestinal tolerance requires gut homing and expansion of FoxP3+ regulatory T cells in the lamina propria. Immunity 34, 237-246 (2011).

29. Tai, X., Cowan, M., Feigenbaum, L. \& Singer, A. CD28 costimulation of developing thymocytes induces Foxp3 expression and regulatory T cell differentiation independently of interleukin 2. Nat. Immunol. 6, 152-162 (2005).

30. Tang, Q. et al. Cutting edge: CD28 controls peripheral homeostasis of CD4+CD25+ regulatory T cells. J. Immunol. 171, 3348-3352 (2003).

31. Schmidt, E.M. et al. Ctla-4 controls regulatory T cell peripheral homeostasis and is required for suppression of pancreatic islet autoimmunity. J. Immunol. 182, 274-282 (2009).

32. Verhagen, J. et al. Enhanced selection of FoxP3+ T-regulatory cells protects CTLA-4-deficient mice from CNS autoimmune disease. Proc. Natl. Acad. Sci. USA 106, 3306-3311 (2009).

33. Vasu, C., Prabhakar, B.S. \& Holterman, M.J. Targeted CTLA-4 engagement induces CD4+CD25+CTLA-4high T regulatory cells with target (allo)antigen specificity. J. Immunol. 173, 2866-2876 (2004).

34. Almeida, A.R., Legrand, N., Papiernik, M. \& Freitas, A.A. Homeostasis of peripheral CD4+ T cells: IL-2R alpha and IL-2 shape a population of regulatory cells that controls CD4+ T cell numbers. J. Immunol. 169, 4850-4860 (2002)

35. Watanabe, K. et al. Cytotoxic-T-lymphocyte-associated antigen 4 blockade abrogates protection by regulatory $T$ cells in a mouse model of microbially induced innate immune-driven colitis. Infect. Immun. 76, 5834-5842 (2008)

36. Phan, G.Q. et al. Cancer regression and autoimmunity induced by cytotoxic T lymphocyte-associated antigen 4 blockade in patients with metastatic melanoma. Proc. Natl. Acad. Sci. USA 100, 8372-8377 (2003).

37. Chikuma, S. \& Bluestone, J.A. Expression of CTLA-4 and FOXP3 in cis protects from lethal lymphoproliferative disease. Eur. J. Immunol. 37, 1285-1289 (2007).

38. Wing, K. et al. CTLA-4 control over Foxp3+ regulatory T cell function. Science 322, 271-275 (2008).

39. Butte, M.J., Keir, M.E., Phamduy, T.B., Sharpe, A.H. \& Freeman, G.J. Programmed death-1 ligand 1 interacts specifically with the B7-1 costimulatory molecule to inhibit T cell responses. Immunity $\mathbf{2 7 , 1 1 1 - 1 2 2}$ (2007).

40. Zeng, M., Guinet, E. \& Nouri-Shirazi, M. B7-1 and B7-2 differentially control peripheral homeostasis of CD4(+)CD25(+)Foxp3(+) regulatory T cells. Transpl. Immunol. 20, 171-179 (2009).

41. Collins, A.V. et al. The interaction properties of costimulatory molecules revisited. Immunity 17, 201-210 (2002).

42. Pentcheva-Hoang, T., Egen, J.G., Wojnoonski, K. \& Allison, J.P. B7-1 and B7-2 selectively recruit CTLA-4 and CD28 to the immunological synapse. Immunity 21, 401-413 (2004).

43. Zheng, Y. et al. CD86 and CD80 differentially modulate the suppressive function of human regulatory T cells. J. Immunol. 172, 2778-2784 (2004).

44. Walunas, T.L. et al. CTLA-4 can function as a negative regulator of $T$ cell activation. Immunity 1, 405-413 (1994).

(c)

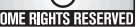

This work is licensed under the Creative Commons Attribution-NonCommercial-No Derivative Works 3.0 Unported License. To view a copy of this license, visit http://creativecommons.org/licenses/by-nc-nd/3.0/ 